\title{
La desigualdad, esencia en el modelo de libre mercado*
}

doi: http://dx.doi.org/10.32870/

espiral.v22i62.258.g288

Maximiliano Gracia Hernández•

El texto de referencia fue publicado originalmente con el título: The price of inequality: how today's divided society endangers our future. Las excelentes aportaciones teóricas y empíricas del autor a lo largo de varios años, lo hacen ser uno de los mejores economistas de nuestro tiempo. En el prefacio del texto se responde acertadamente a la siguiente pregunta: ¿por qué nuestro sistema económico no está funcionando para la mayoría de los estadounidenses? La respuesta se presenta a lo largo de los diez capítulos en los cuales se divide la obra.

El primer capítulo denominado: El problema de Estados Unidos con el 1 por ciento, muestra la tragedia económica que sufrió la sociedad norteamericana con la crisis del 2007-2008, la clase media fue vapuleada por las constantes crisis cuyo impacto hizo que muchos norteamericanos perdieran su dinero o su patrimonio invertido en vivienda hipotecada. En contraste, solo el 1 por ciento de los norteamericanos ganaron con esta crisis. Los ricos se estaban haciendo cada vez más ricos y los pobres cada vez más pobres. La clase

*Agradezco la aportación de Karina Guadalupe Carrillo Torres, becaria en el verano de investigación 2014, por su esfuerzo al sistematizar esta reseña y aportar su conocimiento en la elaboración de la misma.



Joseph E. Stiglitz (20I2). El precio de la desigualdad: El I \% de la población tiene lo que el $99 \%$ necesita. Barcelona: Taurus.

Espiral, Estudios sobre Estado y Sociedad

Vol. XXII No. 62 」 Enero / Abril de $2015 \quad 243$ 
media estaba siendo exprimida, tal y como lo argumenta Krugman al afirmar: "La crisis ha agravado estas desigualdades en innumerables aspectos, más allá del aumento del desempleo, de las viviendas embargadas, de los salarios congelados. Los ricos tenían más que perder en los valores que cotizan en bolsa, pero dichos valores se han recuperado razonablemente bien y relativamente de prisa" (p. 48).

Es interesante escuchar a uno de los grandes economistas norteamericanos argumentar que Estados Unidos es el país más poderoso del mundo, sin embargo tiene una sociedad desigual y con falta de oportunidades para sus ciudadanos. "A lo largo de las últimas décadas, quienes perciben salarios bajos han visto aumentar sus salarios tan solo en un 15 por ciento, mientras que los que están en el 1 por ciento más alto han experimentado un aumento de casi 150 por ciento" (p. 50).

A lo largo del segundo capítulo denominado: La búsqueda de rentas y la creación de una sociedad desigual, al gobierno se le imputa la responsabilidad por la desigualdad, para el autor, la intervención del gobierno para crear una sociedad desigual surge del sistema capitalista, y es que el pago de impuestos de la clase media y baja se distribuye entre la población de manera poco clara y transparente, al respecto Krugman argumenta:

Nuestro sistema político ha venido funcionando cada vez más de una forma que incrementa la desigualdad de resultados y reduce la igualdad de oportunidades, tenemos un sistema político que concede un desmedido poder a los de arriba, y estos han utilizado ese poder no sólo para limitar el alcance de la redistribución, sino también para conformar las reglas del juego en beneficio propio (p. 76).

Los que están en la cima de la riqueza son los grandes hombres que saben hacer negocios, los que están dentro del mundo empresarial, pero no los verdaderos genios quienes 
aportan algún invento o creación tecnológica a la sociedad, entonces ¿en qué se basan los hombres para hacer riquezas? Esta riqueza debería pertenecer a esos grandes genios, a esas personas que con su coeficiente intelectual logran hacer una aportación a la humanidad, pero la realidad es otra, los acumuladores de riqueza son los que tienen la capacidad de vender esos inventos y cerrar un buen negocio, o incluso los que aprovechan las oportunidades y se benefician de los demás. Al respecto el autor argumenta:

Muchas de las formas mediante las cuales nuestro actual proceso político ayuda a los ricos a expensas de los demás, como: transferencias y subvenciones ocultas y públicas por parte del gobierno, leyes que hacen menos competitivos los mercados, una aplicación laxa de las vigentes leyes sobre competencia y unos estatutos que permiten a las grandes empresas aprovecharse de los demás, o trasladar sus costes al resto de la sociedad (p. 8I).

Un factor determinante para realizar un análisis económico de Estados Unidos radica en el incremento de la productividad, la cual es resultado de cambios tecnológicos en muchas empresas estadounidenses, se remplaza la mano de obra cualificada, lo cual genera más productividad, pero también más desempleo. Hoy, ya que no es necesario invertir en salarios cuando se puede invertir en tecnología, la cual ofrece más productividad. Las ideas antes señaladas se enmarcan dentro del capítulo tercero denominado: Los mercados y la desigualdad.

Otro elemento importante para la existencia de desigualdad de riquezas es la discriminación. Estudios realizados en torno a los salarios demuestran que la discriminación de género entre mujeres, afroamericanos, e hispanos es evidente, lo cual influye en la desigualdad existente. Por qué es importante es el título del cuarto capítulo, en él, Krugman hace la siguiente reflexión: 
Cuando los más ricos utilizan su poder político para beneficiar en exceso a las grandes empresas que ellos mismo controlan, se desvían unos ingresos muy necesarios hacia los bolsillos de unos pocos, en vez de dedicarse en beneficio de la sociedad en general (p.l35).

El mal manejo del crédito es una realidad en Estados Unidos, el préstamo que los bancos ofrecen para activar la economía estadounidense no funciona, y es que las personas utilizan en forma inadecuada sus créditos hasta ser insolventes, cuando esto sucede en forma generalizada, se cae en recesión. El problema para Krugman radica en que los bancos ofrecen intereses elevados, no controlan los créditos que ofrecen y las personas se endeudan al máximo de sus posibilidades financieras.

Otro problema origen de la desigualdad es el consumismo: las preocupaciones de los individuos con su consumo en relación con el de los demás -el problema de no ser menos que el vecino- ayuda a explicar por qué tantos estadounidenses viven por encima de sus posibilidades y por qué tanta gente trabaja tanto y durante tantas horas (p. 147). La economía capitalista representa un régimen de competencia por tener más, las personas de clase media y baja quieren vivir mejor, sin embargo con los salarios paupérrimos recibidos no lo logran, es así como su deseo por tener más los lleva a adquirir artículos o servicios fuera de sus posibilidades, ello a través del endeudamiento, sin embargo a mediano plazo esta situación les perjudicará su calidad de vida: más pago de intereses, la deuda crece, y el ingreso disponible se reduce. El resultado es que haya que vender lo poco que se tiene para pagar la deuda.

Para Krugman existe una democracia en peligro, ese es el tema del quinto capítulo, al respecto hay un frase interesante, la cual se explica dentro del texto: un dólar, un voto. La frase correcta debería ser: una persona, un voto. En la 
actualidad la democracia política no es importante, porque finalmente prevalece el poder del más fuerte.

Hoy la gente es desconfiada, ya no se cierra un negocio con un simple apretón de manos. La frase "mi palabra tiene valor y se cumple" quedó en el pasado, lo anterior es resultado de actos fraudulentos de unos sobre otros, ya sean personas o instituciones. Al respecto Krugman argumenta:

Los gobiernos y las sociedades toman decisiones que se manifiestan a través de las políticas, las leyes y las opciones presupuestarias que, o bien refuerzan ese contrato, o bien lo debilitan. Al permitir una metástasis desbocada de la desigualdad, Estados Unidos está eligiendo el camino de la destrucción del capital social, cuando no del conflicto social (p. 177).

Además de la desconfianza entre unos y otros, las personas también desconfían de los medios de comunicación. Al respecto Krugman se pregunta: ¿cómo quieren que los estadounidenses se sientan seguros si no se les dice la verdad de lo que sucede en el país? Inicialmente el problema radica en que el gobierno no brinda información real a los medios de comunicación: “[...] tal y como están las cosas, los medios son un ámbito donde el 1 por ciento domina la situación. Tienen los recursos para comprar y controlar los medios críticos" (p. 179). Entonces, ¿por qué creer en la información emitida por los medios de comunicación, si ellos son los controladores de la información a beneficio propio, "si se trata de otro elemento que contribuye a crear desconfianza y desilusión: no sólo no hay confianza en la justicia de nuestros sistema político y económico, ni siquiera hay confianza en la información que se ofrece sobre ellos" (p. 179).

Estados Unidos ya no es el mismo país del pasado, el sueño americano de las grandes oportunidades se esfumó, las personas saben que el crecimiento del país solo beneficia a unos cuantos. Estados Unidos está perdiendo ese poder ante sus ciudadanos, ellos piden que ese sistema político 
desaparezca. El sistema capitalista no funciona del todo bien para un país con ese grado de desigualdad. Krugman se pregunta cómo es posible que sólo el 1 por ciento tenga la mayor riqueza en el país. Lo que pasa es que los grandes avances en psicología logran que los más informados tengan poder sobre los menos informados. Los propios estadounidenses no logran percibir el nivel de desigualdad que tiene el país. Sí están conscientes de que existe desigualdad, pero no de su nivel.

En el texto se presentan resultados de una encuesta realizada: los estadounidenses mencionan que el 20 por ciento más alto poseerían tan solo un poco más del 30 por ciento de la riqueza del país. Están en un total error. El desconocimiento del nivel de desigualdad estriba en que las personas no tienen acceso a una información perfecta: si hicieran un uso eficiente de ella en su intento de alcanzar sus metas, unas metas que ellos mismos comprendieran bien, pero el problema es que esto no funciona, en realidad el 1 por ciento sabe más acerca de este tipo de información y la tienen restringida para mantener a la sociedad cautiva de ellos y controlar así el mercado y por ende el aumento de sus riquezas. Las reflexiones anteriores el lector las podrá encontrar en el sexto capítulo de la obra, cuyo título es: 1984 Está al caer.

La manera cómo la mercadotecnia juega con la mente de los consumidores es una causa de la crisis en Estados Unidos, los empresarios siempre están buscando como leer la mente de los consumidores, al medir sus percepciones pueden lograr mayores ventas. Las ideas y las percepciones sobre lo que pasa alrededor de las personas están basadas en las ideas o creencias de los demás, muy pocos individuos se toma el tiempo de investigar por sí mismos lo que los demás afirman y solo por confiar en algunas personas creen en lo que dicen. Estas ideas se convierten en herramienta para los pertenecientes al 1 por ciento. "Quienes desean 
mantener las desigualdades de las sociedades intentan activamente dar forma a las percepciones y las creencias, a fin de hacer más aceptables esas desigualdades. Poseen los conocimientos, las herramientas, los recursos y los incentivos para hacerlo" (p. 210).

En el séptimo capítulo Krugman se pregunta: jjusticia para todos? Cómo la desigualdad está erosionando el imperio de la ley. $\mathrm{Al}$ respecto una serie de reflexiones. Los gobernantes de Estado Unidos se glorifican al afirmar: Estados Unidos es un país libre y soberano en donde las leyes sí se cumplen, pero ¿en realidad se cumplen?, la mayoría de las leyes están hechas para el beneficio de los ciudadanos, pero debemos cuestionar: ¿qué hay acerca de las leyes para el cuidado del medio ambiente?, ¿las empresas que más contaminan ¿pagan por emitir esa contaminación? La respuesta es no, la ley no las obliga a absorber esos costos porque de lo contrario las compañías amenazan al gobierno en despedir a empleados para cubrir esos gastos extras.

Los grupos con poder económico deciden qué hacer con él, ellos mismos establecen sus leyes, deciden si contaminan o no, o si pagan por esa contaminación o no, diseñan su propio sistema económico que los favorece "mediante leyes y normativas que afectan específicamente a una industria, o a través de las normas que rigen las quiebras, la competencia, la propiedad intelectual o los impuestos" (p. 249).

¿Qué sucede si un empleado es despedido? La respuesta la ofrece Krugman cuando afirma:

Las grandes empresas que realmente causan daños pueden tener más fuerza que los damnificados. Es probable que las empresas puedan compensar con una miseria a los damnificados, ya que mucha gente no puede aguantar tanto tiempo a la espera de una indemnización digna, ni puede permitirse pagar unos abogados del mismo nivel que los de la compañía (p. 248).

Reseñas No. 62 
La batalla de los presupuestos es el título del octavo capítulo, en él se discute y analiza la importancia de los impuestos y la lucha para asignar el presupuesto del estado. Estamos ciertos en que la Guerra que enfrenta Estados Unidos y sus repercusiones en el déficit fiscal representan un parte considerable del gasto público. "Estados Unidos estaba gastando como si la guerra fría continuara todavía: sus gastos militares ascendían a la suma de los gastos militares de todos los demás países del mundo juntos” (p. 270).

Krugman propone otra forma de disminuir los presupuestos a través de la creación de una ley tributaria justa: es mejor gravar las cosas malas que las buenas, ya que en vez de gravar el trabajo es mejor gravar la contaminación y con ello se obtendrían mejores resultados para el país. El texto ofrece una serie de datos interesante, por ejemplo: es mejor disminuir los impuestos a la clase baja y aumentar los impuestos a la clase económicamente poderosa, porque el 1 por ciento de la población de Estados Unidos se está llevando el 20 por ciento de la riqueza del país, un aumento del 10 por ciento a sus impuestos generaría el incremento del 2 por ciento de PIB del país, lo que sería benéfico para la mayoría.

El gobierno puede pedir dinero prestado con el objetivo de crear un mejor futuro para su país a través de la inversión en educación, investigación, infraestructura y salud, si hace esto a largo plazo obtendrá su resultado y la desigualdad disminuirá: "Estados Unidos está en una posición especialmente favorable para llevar a cabo esta estrategia, [...] porque la rentabilidad de la inversiones públicas es muy alta" (p. 275).

Krugman detecta el problema actual en Estado Unidos como una falta de demanda, no de oferta. Si el problema fuese la oferta, las grandes empresas podrían invertir en nuevos productos, pero si la clase paupérrima y media no tienen dinero para comprar, entonces lo que se tiene que 
hacer es permitirle a la clase media y baja acceso a un mayor nivel de ingreso. Pensar que las instituciones como el Banco Central y la política macroeconómica actúan para el 1 por ciento es algo que se sale de la realidad, este es el tema del capítulo décimo, en él se argumenta la necesidad de cuidar las variables macroeconómicas, como es el caso de la inflación, y aunque ese no es un problema para la economía de Estados Unidos, si lo es el problema del desempleo. En este marco, los empresarios argumentan la necesidad de flexibilizar el mercado laboral, por supuesto que su objetivo es obtener mayor ventaja:

El propio debilitamiento del sistema de protección social y las presiones para lograr unos mercados laborales más flexibles pueden haber amplificado las consecuencias macroeconómicas de unas políticas monetarias equivocadas (p. 305).

Preguntarnos si es posible otro mundo, son reflexiones del décimo capítulo, por ejemplo, la existencia de monopolios en el país es una de las causas de la desigualdad; al estar el mercado controlado por dos o tres empresas, el afectado es el consumidor. Krugman argumenta que

las empresas dominantes tienen herramientas con las que eliminar a la competencia, e incluso a menudo consiguen eliminar las innovaciones. Los precios más altos que cobran esas empresas no sólo distorsionan la economía, sino que también funcionan como un impuesto (p. 334).

Mejorar y tener más facilidad de acceso a la educación, son retos que se deben enfrentar, así se podría reducir la desigualdad, un pueblo educado puede hacer crecer el PIB del país. El libro relata en cada capítulo los problemas económicos y sociales al interior de los Estados Unidos, además señala sus posibles soluciones, lo cual es una gran 
aportación del texto. En concreto, el texto menciona la desigualdad en que vive el pueblo estadounidense.

Si bien es cierto que en todos los países existe desigualdad de riquezas, Estados Unidos tiene la ventaja de tener una mejor calidad de vida que muchos países en el mundo. En ese sentido podemos afirmar que Estados Unidos es un país capitalista con un buen gobierno, sin embargo los estadounidenses son los únicos que pueden resolver sus problemas internos. 